\title{
The Common European Framework of Reference and the Co-Constructed Language Curriculum
}

\author{
MARIE-THERESE BARBAUX \\ University of Sydney \\ marie-therese.barbaux@sydney.edu.au
}

\begin{abstract}
For the last two decades, the Common European Framework of Reference (CEFR) has been instrumental in the globalisation of language policy not only across Europe but also around the world. The CEFR competency profiles, expressed in action-oriented statements, provide a clear articulation of language proficiency levels. The comprehensive scales of language competence the CEFR have created provide an essential instrument for language professionals and language learners: a shared language. The CEFR scales and statements assist learners in developing an understanding of the standards of performance expected of them, and allow teachers to ensure coherence between desired learning outcomes, classroom activities and assessment tasks, thus bringing a high level of transparency to the language curriculum. Two initiatives making use of the CEFR descriptors will be discussed: the redesign of an entire three year language curriculum and an approach to language curriculum design that gives a voice to students and lead to a collaborative and continuous design process.
\end{abstract}

Keywords: Common European Framework of Reference (CEFR), European Languages, Second Language Acquisition

\section{Introduction}

The Common European Framework of Reference (CEFR) was published in 2001, during the European Year of Languages, and has since been translated in 40 languages. The CEFR development, between 1989 and 1996, was part of the project "Language Learning for European Citizenship". It is now used to describe achievements of learners of foreign languages across Europe and increasingly throughout the world. The CEFR aims to describe "in a comprehensive way what language learners have to learn to do in order to use a language for communication and what knowledge and skills they have to develop so as to be able to act effectively." It defines global standards of language proficiency but its purpose is to provide more than just proficiency scales.

The result of over twenty years of research, the Common European Framework of Reference for Languages: Learning, Teaching, Assessment (CEFR) is exactly what its title says it is: a framework of reference. It was designed to provide a transparent, coherent and comprehensive basis for the elaboration of language syllabuses and

\footnotetext{
${ }^{1}$ Council of Europe, Common European Framework of Reference for Languages: Learning, Teaching, Assessment, Cambridge: Cambridge University Press, 2001, p. 1.
} 
curriculum guidelines, the design of teaching and learning materials, and the assessment of foreign language proficiency. ${ }^{2}$

Language curriculum design is a structured process that aims to provide students with carefully planned learning experiences in order to support them in achieving stated learning objectives. Language teachers have traditionally been preoccupied with the definition of the language syllabus, i.e. the content knowledge and skills that students need to acquire. In recent times, language professionals have distanced themselves from the notion of syllabus and focused more on the understandings and capacities that students need to develop. The learning objectives, or learning outcomes, are different in the two instances. On one hand, the focus is primarily on knowledge, and on the other, it is on capabilities and actions.

The CEFR belongs to the second category. It expresses learning objectives, or outcomes, as 'can-do' statements - as in, for example: "can produce essays or reports which develop an argument, giving reasons in support of or against a particular point of view and explaining the advantages and disadvantages of various options"3.

A language syllabus is centred around the content to be covered, its sequential organisation and how its acquisition by students will be assessed. By focusing on proficiency descriptions (on what language learners "can do"), the CEFR allows educational institutions and language practitioners to define the learning plan that best suits their learners and their context. The CEFR is a "framework" and therefore is far removed from a prescriptive language program. The spirit of non-imposition and freedom of use and the adaptability of the CEFR has guaranteed its international influence and the crucial role it has played over the last two decades in the teaching and learning of languages around the world. Responding to criticisms of the imprecision and lack of directive of the CEFR, Brian North, one of the co-authors, emphasised that it is meant to be a reference tool, not a method:

The CEFR draws on theories of communicative competence and language use in order to describe what a language user has to know and do in order to communicate effectively and what learners can typically be expected to do at different levels of proficiency. It doesn't try to define what should be taught (content specifications), let alone state how it should be taught (methodology). ${ }^{4}$

One of the CEFR's objectives was to "establish a metalanguage common across educational sectors, national and linguistic boundaries that could be used to talk about objectives and language levels." 5 Whereas it did not seek to be directive, it called for a change in teaching practices in order to improve mobility, understanding and cooperation among Europeans. The ambition of the Council was thus to provide a fundamental instrument that would support and empower people in communicative

\footnotetext{
${ }^{2}$ Council of Europe, Common European Framework of Reference for Languages: Learning, Teaching, Assessment (CEFR), 2014, accessed 17 April 2016, http://www.coe.int/t/dg4/linguistic/cadre1_en.asp

3 Common European Framework of Reference for Languages: Learning, Teaching, Assessment, Cambridge University Press, 2001, p. 62.

4 Brian North, 'Europe's Framework Promotes Language Discussion, Not Directives, Education Guardian [online edition], April 15, 2004, https://www.theguardian.com/education/2004/apr/15/tefl6, accessed 4 July 2016. 5 Brian North, The Common European Framework of Reference for Languages (CEFR) and the Development of Language policies: Challenges and Responsibilities, Policy Forum, Council of Europe Language Policy Division, Strasbourg, 6-8 February 2007, accessed 23 April, 2016,

https://www.coe.int/t/dg4/linguistic/Source/SourceForumo7/North-Forum-paper_EN.doc
} 
situations. According to the Council of Europe, language learning is for the learner and should therefore give learners a voice.

The two initiatives presented in this article are well suited to the main characteristics of the CEFR outlined above. The review of a three year language curriculum makes use of the proficiency statements and language levels defined by the Framework and adopts these statements as desired learning outcomes for all its units of study. Likewise, the proposed co-constructed language curriculum model aims to give a voice and some influence to students in the curriculum design process. After outlining the relevant features of the CEFR, this article will articulate how the CEFR descriptors can help anchor coherence and transparency in the design of the language curriculum and will then examine the illuminative role of the CEFR in terms of students' understanding of expectations during the implementation of the curriculum in the classroom. Finally, the co-constructed curriculum model and its rationale will be discussed.

\section{The Common European Framework of Reference}

The Framework has a vertical and a horizontal dimension. The vertical dimension defines six levels of communicative proficiency in three bands, corresponding loosely to the universally accepted levels of beginner, intermediate and advanced. 6

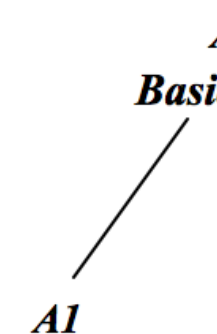

(Breakthrough)
$\boldsymbol{A}$

\section{User}

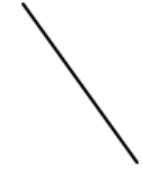

$A 2$

(Waystage)

$\boldsymbol{B}$

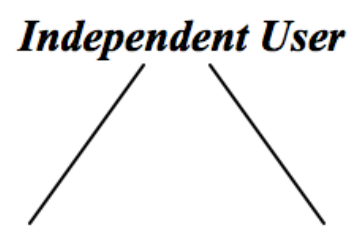

B1

(Threshold)
B2

(Vantage)

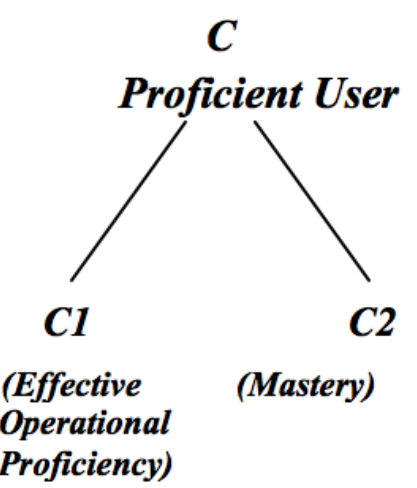

Figure 1. CEFR's six levels of proficiency ${ }^{7}$

The CEFR has had a massive impact and has become "a powerful instrument for shaping language education policies in Europe and beyond." 8 However, the authors of the CEFR insist that it offers neither standards nor norms, and underline the fact that it is a set of guidelines for describing language learners' achievements and a reference document for teachers and language practitioners: "The CEFR is purely descriptive -

\footnotetext{
${ }^{6}$ David Little, The Common European Framework of Reference for Languages: Content, Purpose, Origin, Reception and Impact, Language Teaching, 2006, p. 39, pp. 167-190.

7 Waldemar Martyniuk, Annual Meeting of the Consortium for Language Teaching

and Learning, Ithaca, NY: Cornell University, May 5, 2006, p. 6.

${ }^{8}$ Waldemar Martyniuk, 'The Council of Europe's Common European Framework of Reference for Languages (CEFR): Approach, Status, Function and Use,' Language Learning in Higher Education, Vol. 1, No. 1, 2011 : pp. 23-40, p. 34 .
} 
not prescriptive, nor normative."9 They vigorously reject the notion of standardisation and put forward the need for plurality, independence and empowerment:

One thing should be made clear right away. We have NOT set out to tell practitioners what to do, or how to do it. We are raising questions, not answering them. It is not the function of the Common European Framework to lay down the objectives that users should pursue or the methods they should employ. ${ }^{10}$

The CEFR is intended to facilitate the mutual recognition of language qualifications across the world and promote co-operation among language professionals and educational institutions. It is offered as a basis for sustained international co-operation in the development of language education policy, the construction of language curricula and implementation of language learning and teaching, and the assessment of language learning outcomes. To this end, the CEFR seeks to be:

- comprehensive: specifying "as full a range of language knowledge, skills and use as possible,",11

- transparent: "information must be clearly formulated and explicit, available and readily comprehensible to users," 12

- coherent: the descriptors should be "free from internal contradictions."13 Language learning needs to be planned as a whole process, specifying outcomes, ways of measuring learner achievement, learning materials and teaching methods,

- multidimensional and action-oriented: language curricula need to be based on learning outcomes defined in terms of the language competence needed for the actions and communication tasks that the learners are likely to face,

- supportive of lifelong learning: language learning is a dynamic lifelong process that needs to equip learners for changing situations in life, and

- supportive of student autonomy: autonomous learning and self-assessment are key concepts of the CEFR approach to learning. Learner autonomy - i.e. learners' ability to plan and evaluate their own learning - is at the heart of the CEFR. The European Language Portfolio, developed for language learners by the Language Policy Division as a complement to the CEFR, allows students to record over time their language learning experiences and outcomes in and outside of the classroom.

These fundamental principles and characteristics of the CEFR form the core concepts of the model of co-constructed curriculum design model that will be described later in this paper. In the proposed model, the CEFR statements of competency, used as learning outcomes, provide the foundation of the coherent, transparent and multidimensional language curriculum the model advocates.

\section{Curriculum Coherence and Transparency}

The notion of curriculum coherence implies that the main curriculum components are aligned and mutually supportive. In a coherent curriculum, learning outcomes,

\footnotetext{
${ }_{9}^{9}$ Council of Europe. Recommendation CM/Rec(2008)7 of the Committee of Ministers to member states on the use of the Council of Europe's Common European Framework, 2008, p. 9.

${ }^{10}$ Common European Framework of Reference for Languages: Learning, Teaching, Assessment, Cambridge:

Cambridge University Press, 2002.

11 ibid., p. 7.

12 ibid.

13 ibid.
} 
assessment tasks and learning activities all concur and form a united whole: they are "constructively aligned." 14 The message they are sending to students is cohesive and clear and guides them in their understanding of what is expected (in assessment) and what to do to fulfil those expectations (how to learn).

The key is that the components in the teaching system, especially the teaching methods used and the assessment tasks, are aligned to the learning activities assumed in the intended outcomes. The learner is in a sense "trapped", and finds it difficult to escape without learning what is intended should be learned. ${ }^{15}$

Coherence brings transparency and transparency increases students' understanding of the rationale behind each assessment task and the standard of performance expected. This approach requires learning outcomes that are based on performance and defines what the learners will be able to "do" rather than simply know or understand. Outcomes are expressed in the form of observable and measurable actions and behaviours. They specify what the student will be able to do, not what the teacher will teach. It is not a question of how much content will need to be covered in class but what students will be able to demonstrate at the end of the period of study.

This approach represents the gradual evolution from syllabus design to curriculum planning in language curricula. The language syllabus typically described the content to be taught and the methods used to teach it. The language curriculum is preoccupied with students' capacities at the end of the course or degree program. The notion of syllabus as the pre-packaged language content primarily determined by the teacher has given way to a concept of curriculum constituted of tasks performed within the social processes of the classroom. ${ }^{16}$ In the language curriculum, learning tasks consistently engage students through the development of the skills, knowledge and understandings set out by the learning outcomes. Assessment tasks measure students' accomplishments towards the learning outcomes and indicate whether the required standard of achievement has been met.

Teachers developing a fully aligned language curriculum use a design process that is different from the traditional language syllabus design. Rather than first determining which content needs to be taught and how it needs to be organised, the teacher will first identify the core capabilities that students will need to meet at the end of the course. She will then consider how she will know when students have achieved those core capacities, i.e. which assessment tasks will adequately measure achievement of the learning outcomes. It is only in a third stage that she will plan the teaching and learning activities, materials and tasks that will prepare students for the assessment tasks.

\footnotetext{
${ }^{14}$ John Biggs, 'Aligning teaching and assessment to curriculum objectives,' Higher Education Academy, September 1, 2003, accessed 5 July 2016,

https://www.heacademy.ac.uk/resources/detail/resource_database/id477_aligning_teaching_for_constructing_ learning.

15 ibid.

${ }^{16}$ Michael P. Breen, 'Contemporary Paradigms in Syllabus Design: Part 1,' Language Teaching, Vol. 20, No. 1, 1987: pp. 81-92; Michael P. Breen, ‘Contemporary Paradigms in Syllabus Design: Part 2,' Language Teaching, Vol. 2O, No. 1, 1987: pp. 157-174.
} 


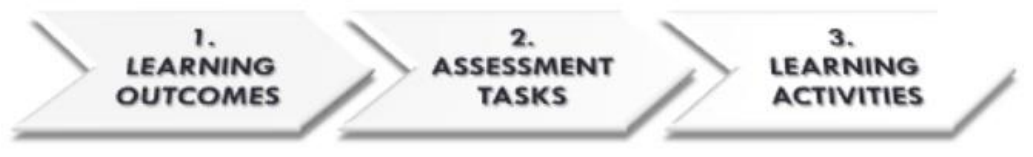

Figure 2. Curriculum design sequence

The design process has been reversed, starting with the end result and then creating the conditions and contexts that will allow students to achieve it. This requires a deliberate alignment between the planned learning activities, assessment tasks and learning outcomes and a conscious effort to provide the learner with a clearly specified goal, well-designed learning activities that are appropriate for the task, and welldesigned assessment criteria that measure achievement towards the given goal and give valuable feedback to the learner.

Such approach follows the "Backward Design Model" advocated by Wiggins and McTighe, which contends that learning experiences should be planned with the final assessment in mind. Teaching to the end-point ensures that the knowledge and skills being taught remain focused and structured towards the goals. In their book Understanding by Design, Wiggins and McTighe emphasise the critical role played by understanding in student learning and the need for the design process to ensure coherence between the final outcome, assessments and classroom activities so that students' awareness and understanding of the requirements are constantly reinforced. ${ }^{17}$

In a university language program, consisting of three or four years of study, the role of the CEFR statements of competency is invaluable as it outlines a coherent progression of student competencies over the years and make this progression explicit and transparent. The Department of French Studies at the University of Sydney has undertaken over the last four years a complete redesign of its three-year language curriculum. It adopted a variation of the "backward design" approach which started with a detailed analysis of the existing assessment tasks in the three-year French curriculum.

The process went through four stages:

- First, the CEFR statements of competency were adapted for university study at all levels, from $\mathrm{A} 1$ to $\mathrm{C} 1$.

- Secondly, the re-written CEFR statements were adopted as the main learning outcomes in the four competencies (speaking, listening, reading and writing) for all language units of study in the three language streams (introductory, intermediate and advanced).

- Thirdly, each assessment task used in the three years of the French major in each of the three language streams was analysed to determine their alignment with the appropriate CEFR level, the balance of assessment tasks across the four competencies and the types of tasks (targeted skill, surface or deep learning approach, etc.).

- Finally, vertical (from first to third year) and horizontal (across language levels) misalignments were identified, leading to a redesigned degree structure over the three years and the three language streams.

${ }_{17}$ Grant Wiggins \& Jay McTighe, Understanding by Design, $2^{\text {nd }}$ Edition, Alexandria, VA: Association for Supervision and Curriculum Development (ASCD), 2005. 
The adoption of the CEFR statements of competency as learning outcomes for all units of study taught in the department constrained each unit firstly to adopt competencies (and not content) as main learning outcomes and secondly to devise assessment tasks able to measure achievement toward the competencies. Assessment design thus became the driver in the re-design of the departmental curriculum, not only allowing for external visibility but also ensuring parity across language streams.

\section{The Negotiated Curriculum}

A coherent curriculum aims to give students well-designed opportunities to achieve the intended outcomes and to ensure they develop a good understanding of the expected standards of performance. However, a curriculum - in particular, a language curriculum - is not a top-down process: that is, a series of structured learning-related activities determined before teaching begins which stays unchanged in the course of the teaching and learning process. The classroom is a curricular space. An effective and engaging classroom - and this is increasingly true for its online versions as well - is a space of constant re-negotiation of the pre-determined curriculum. An effective classroom gives full credit to learner agency and emphasises the co-construction of the learning experience with the teacher.

The divergence between the curriculum plan and its implementation in the classroom has long been acknowledged. Breen stated that "a syllabus can only have, at best, an indirect influence upon actual language learning. It is mediated by teaching and the encircling classroom context within which instruction is only one element." 18 Breen made the distinction between the pre-planned curriculum and its actual implementation with students and put forward the notion of "process curriculum," in which the curriculum, or aspects of it, are constantly negotiated between the teacher and students. ${ }^{19}$ The very existence of a curriculum depends on its enactment in the classroom: "A curriculum cannot exist BEFORE it is enacted. Or, put another way, curriculum must be enacted to exist." 20 The concept of "enactment" of the curriculum in the classroom was first suggested by Barnes:

When people talk about "the school curriculum" they often mean "what teachers plan in advance for their pupils to learn". But a curriculum made only of teachers' intentions would be an insubstantial thing from which nobody would learn much. To become meaningful a curriculum has to be enacted by pupils as well as teachers. [...] A curriculum as soon as it becomes more than intentions is embodied in the communicative life of an institution. In this sense curriculum is a form of communication. $^{21}$

A curriculum must be enacted to generate learning experiences. The curriculum is the sum of educative experiences created jointly by teacher and students who reconstruct and recreate it through their experience within the teaching and learning context, in and out of the classroom. Snyder et al. describe "how curriculum is shaped through the

\footnotetext{
${ }^{18}$ Breen, 'Part 1,' pp. 81-92; Breen, 'Part 2,' p. 159.

${ }_{19}$ Michael P. Breen \& Andrew Littlejohn, Classroom Decision-Making: Negotiation and Process Syllabuses in Practice, Cambridge: Cambridge University Press, 2000.

${ }^{20}$ Kathleen Graves, 'The Language Curriculum: A Social Contextual Perspective,' Language Teaching, Vol. 41:2, 2008: pp. 147-181. Emphasis in original.

${ }^{21}$ Douglas Barnes, From Communication to Curriculum, London: Penguin Books, 1976, p. 14.
} 
evolving constructs of teachers and students". ${ }^{22}$ This concept of curriculum as a permanent re-creation is markedly different from the traditional notion of curriculum as a product that is delivered and then reviewed at the end of the teaching period. The traditional curriculum model follows a cycle of planning, teaching, evaluating and reviewing. ${ }^{23}$ There is always a gap between what the teacher had planned and how the planned curriculum is received by students. Since the traditional curriculum is evaluated - as a product - at the end of the period of study through student questionnaires, the gap cannot be corrected for current students and changes will apply only to the next cohort of students, if applied at all. Effective and attentive teachers do make - usually small - changes to the curriculum during the teaching period in response to student reactions and spontaneous or solicited feedback. This is often viewed as "fine-tuning" the curriculum and is left entirely to the discretion of the teacher. However, greater changes which result from formal student evaluation have to wait until the next teaching period. The crucial contribution of student feedback is only present after the teaching phase and students are rarely considered as a legitimate party to the curriculum design process. There is no direct accountability to the student cohort that provided the evaluation and suggestions for improvement.

This paper proposes to extend the scope and time of the student evaluation of the unit of study and integrate student feedback during the period of study, as an integral part of the curriculum. In other words, it proposes to add a reflective aspect to the enactment of the curriculum, a critical and continuous evaluation that will assist, on an on-going basis, teachers' curriculum re-evaluation. Such critical student feedback during the course of a study period, and the almost immediate resulting actions by the teacher, are usually absent from the main curriculum theories. Richards describes curriculum development as " the range of planning and implementation processes involved in developing or renewing a curriculum." 24 It is clear that curriculum renewal is typically seen as an outcome of the final student evaluation at the completion of the course.

What is proposed here is to define and analyse the place and role of student feedback within the curriculum framework, and to set up a process that integrates informed and reflective student feedback in the classroom as an integral and consistent part of the teaching and learning process. The conception of the classroom as an "ecology" where students are seen as members of a group that shape their environment is useful here. The "classroom ecology paradigm" was first defined by Doyle 25 and developed further by van Lier. ${ }^{26}$ Doyle was concerned with the link drawn by traditional curriculum models between student learning and teacher behaviours. The way teachers' actions influenced student learning was not explained. The assumption was that the teacher was directly causing student learning. It is, however, not simply a matter of input and

\footnotetext{
22 Jon Snyder, Frances Bolin, \& Karen Zumwalt, 'Curriculum Implementation,' in Handbook of Research on Curriculum, ed. Philip Jackson, New York: Macmillan, 1992, pp. 402-435, p. 404.

${ }^{23}$ Ralph W. Tyler, Basic Principles of Curriculum and Instruction, Chicago: University of Chicago Press, 1949.

24 Jack C. Richards, Curriculum Development in Language Teaching, Cambridge: Cambridge University Press, 2001, p. 41.

${ }_{25}$ Walter Doyle, Paradigms for Research on Teacher Effectiveness, in Review of Research in Education, ed. LSLee S. Schulman, Itasca, IL: E.E. Peacock, 1977, pp. 163-198.

${ }^{26}$ Leo van Lier, 'From Input to Affordance: Social-Interactive Learning From an Ecological Perspective,' in Sociocultural Theory and Second Language Learning, ed. James Lantolf, Oxford: Oxford University Press, 200o, pp. 245-26o.
} 
output. ${ }^{27}$ The ecological classroom model describes an environment with opportunities for action and participation from students.

In the same way, the concept of curriculum enactment implies a dynamic process and highlights the agency of both teacher and learners. It is a process "jointly created, and jointly and individually experienced by students and teacher." ${ }^{28}$ In the curriculum enactment approach, curriculum knowledge is a constant construction through "the enacted experiences... [that] students and teacher create." 29 Curriculum change becomes "a process of growth for teachers and students, a change in thinking and practice." 30 It is a form of "classroom-level curriculum development." ${ }^{1}$ For Ewing, a curriculum includes a number of storylines, teacher's and students' narratives. ${ }^{2}$ It is a dynamic discourse and is "lived" by all participants. 33 It includes both top-down and bottom-up processes. In brief, the enactment of a curriculum is a unique social context that gives agency to all participants. It highlights the fundamental interdependence between all the actors, teachers and students, in the educational context.

A curriculum is essentially multi-dimensional. Curriculum descriptions have traditionally been limited to two dimensions, on one hand content and its organisation and on the other, the learning and assessment activities that they support. Increasingly, a third dimension is being included by educational and discourse theorists, adapted from the concept of third space. Parallels have been drawn between the educational context, and its intercultural nature, and the notions of first, second and third space. 34 For Edward Soja, "Thirdspace" originates from the tension between real and imagined space. "Firstspace" is the concrete space of social institutions, such as the office or the stadium, where interactions and behaviours are constrained by social roles. "Secondspace" is mainly constituted of plans and planning documents, attempting to construct, re-imagine and order the Firstspaces. In the educational context, the physical buildings (e.g. the classrooms) as well as the structures (e.g. grades, policies, class size, teaching staff, etc.) constitute the Firstspace, while the Secondspace includes educational planning, its rationale, the planned curricula and their organisation and structure. There are both connections and disjunctions between Firstspace and Secondspace. The physical and structural constraints of Firstspace limit the reinvention and reconstruction of the Secondspace plans that in turn attempt to renew and redesign the Firstspaces. The difference between Soja's Firstspace and Secondspace relates to Foucault's notions of "real" and "ideal" spaces 35 or Lefebvre's distinction between "perceived" and "conceived" spaces. ${ }^{36}$ In the context of education, the curriculum, as an educational plan, represents a Secondspace or an "ideal" and "conceived" space. It is an idealised and ordered view of teaching and learning interactions and outcomes. The classroom and online environments, with their social and interrelational processes, are the spaces of junction and friction between the

\footnotetext{
27 ibid.

${ }^{28}$ Snyder et al. 'Curriculum Implementation,' p. 428.

29 ibid, p. 410.

30 ibid, p. 429.

${ }^{31}$ Saad F. Shawer, Deanna Gilmore \& Susan R. Banks-Joseph, 'Student Cognitive and Affective Development in the Context of Classroom-level Curriculum Development,' Journal of the Scholarship of Teaching and Learning, Vol. 8, No. 1, February 2008: pp. 1-28, p. 3.

$3^{2}$ Robyn Ewing, Curriculum and Assessment: Storylines, South Melbourne: Oxford University Press, 2013.

33 Henry Lefebvre, La Production de l'Espace, Paris: Anthropos, 1974.

34 Edward Soja, Thirdspace: Journeys to Los Angeles and Other Real-and-Imagined Places, Oxford: Blackwell, 1996.

35 Michel Foucault, Surveiller et Punir, Naissance de la Prison, Paris: Gallimard, 1975.

${ }^{36}$ Lefebvre, La Production de l'Espace.
} 
educational institutional framework and the curriculum, its educational plan. They are the third spaces where multiple discourses and interpretations take place and the curriculum plan is subjected to both engagement and resistance. Assumptions and strategies from teacher and students are at play through the dynamic and dialectic nature of the teaching and learning process. This is why the curriculum is being enacted and reinvented in Thirdspace. It is a space of "otherness" ("un espace autre"), a heterotopia with multiple layers of meaning and representation. 37 The same curriculum space within the same educational framework will be applied and enacted in different ways by different classes, different groups of students and different teachers. It is the manifestation of difference and imagination as well as a means to escape from the directive and prescriptive power of first and second space. The enactment of the curriculum - both in the classroom and, increasingly, online - is pluralistic and highly socialised. 38

In the Thirdspace of the enacted curriculum, students continually seek to interpret, elucidate and decode the curriculum: their need for clarification, repetition, reconceptualisation and sometimes overt or disguised resistance alter the curriculum pace and content. In so doing, they rewrite the curriculum. The learning space becomes a construct of their experiences, interpretations and interactions 39 . Blasco outlines the difference between what has been planned (in Secondspace) and what is being experienced by the students during the learning process (in Thirdspace):

learning [...] is not an automatic result of tight organization, planned outcomes and dense content delivery but ultimately arises from about students' lived experiences of education, which are not so readily controlled. ${ }^{40}$

"Curriculum" comes for the Latin "currere," meaning "to run." It is not a static concept, it moves and changes under the impetus of not only the teacher, but finds of equal importance, students' perceptions and narratives, constructions and re-constructions, and constant negotiations of meaning. With multiple storylines, it is a dialogic and creative space. ${ }^{41}$ The classroom and the enacted curriculum represent a "lived space," le vécu, where the space is not a simple and mainly passive environment but is socially shaped by the activity of its occupants. $4^{2}$ Thus students are active participants and decision-makers in the learning space, an experiential space that is "generating rather than disseminating knowledge." 43

Even though the perception of students as passive recipients of the knowledge delivered to them is still widespread in education, a significant number of learning theories and approaches have demonstrated that learners are, when given a chance, active practitioners of learning and readily take ownership of their learning process. Van Lier's ecological classroom provides students with opportunities for purposeful

\footnotetext{
37 Michel Foucault, 'Des Espaces Autres,' Architecture, Mouvement, Continuité, Vol. 5, 1984: pp. 46-49.

${ }^{38}$ For the application of Foucault's concepts of heterotopia and panopticon to student online discussions, see Mark Warschauer, 'Heterotopias, Panopticons, and Internet Discourse,' University of Hawaii Working Papers in ESL, Vol. 14, No. 1, 1995: pp. 91-121.

39 Alice Y. Kolb \& David A. Kolb, 'Learning Styles and Learning Spaces: Enhancing Experiential Learning in Higher Education,' Academy of Management Learning \& Education, Vol. 4, No. 2, 2005: pp. 193-212.

40 Maribel Blasco, 'Conceptualising Curricular Space in Busyness Education: An Aesthetic Approximation,'

Journal of Management Learning, Vol. 47, No. 2, 2016: pp. 117-136.

${ }^{41}$ Ewing, Curriculum and Assessment.

42 Lefebvre, La Production de l'Espace.

43 William Savage, 'Language and Development,' in Language and Development: Teachers in a Changing World, eds. Brian Kenny and William Savage, London: Longman, 1997, p. 293.
} 
activity that create meaning, relevance and engagement. 44 Allwright and Hanks' exploratory practice sees language learners as key developing practitioners of learning, and not just targets of teaching:

by insisting on the term practitioner we want to make it easier to see the learner's role as importantly parallel to the role of the people we already happily see as "practitioners" - the teachers. Teachers are officially in charge of the practice of language teaching in the classroom, but they have to leave the actual practice of language learning to the learners. Only the learners can do their own learning. And it is their parallel practice as learners that either will or will not effectively complement the efforts of teachers. ${ }^{45}$

In the same way, Kenny's experiential learning approach places learner autonomy at the centre of the teaching and learning interactions. In the experiential curriculum, students have control over the content and process of learning:

An experiential syllabus is essentially an organisation of people. Its participants learn from experience and reflections as they investigate issues they have identified as of pressing concern and interest to them. ${ }^{46}$

Increasingly, in educational theory, the collaborative and participative nature of classrooms and other group learning contexts is being acknowledged and analysed. This body of research aligns itself well with the spirit of the CEFR development and the democratic intentions of the Council of Europe.

Similarly, to support effective and engaged student learning, the co-constructed language curriculum approach outlined below aims to nurture democratic processes in the classroom and gives students a voice in the ongoing evaluation and re-design of the language curriculum they are participating in.

\section{Co-constructed Curriculum Model}

The model of the co-constructed curriculum proposed in this paper is built upon the three components and concepts developed above: CEFR competency profiles, curriculum coherence and student negotiation. The CEFR descriptors provide the desired end results - the learning outcomes - around which the design of assessment tasks and learning activities is aligned prior to teaching. Student negotiation occurs during the teaching and learning period around assessment tasks. We will now attempt to describe the classroom process leading to the co-construction of the language curriculum.

Assessment is the core to the model since assessment provides a specific context to the learning outcomes, and in so doing provides a way for students firstly to develop an understanding of the desired outcomes and secondly to judge the effectiveness of learning activities in helping to achieve them. Students are best placed to critically evaluate the effectiveness of the curriculum, how assessment tasks allow them to demonstrate achievement towards the learning outcomes (as specified by the CEFR

\footnotetext{
44 Leo van Lier, The Ecology and Semiotics of Language Learning: A Sociocultural Perspective, Norwell, MA: Kluwer Academic Publishers, 2004.

45 Dick Allwright \& Judith Hanks, The Developing Language Learner: An Introduction to Exploratory Practice, Basingstoke: Palgrave Macmillan, 2009, p. 2.

${ }^{46}$ Brian Kenny, 'Knowledge, Experience and Language Teaching,' System, Vol. 24, No. 4, 1996: pp. 449-460, p. 451.
} 
competencies) and how learning activities, in and outside of the classroom, prepare them for the assessment tasks. As Graves outlined,

Assessment is concerned with documenting over time the learners' progress and achievement in meeting the curricular goals. As such, assessment bridges planning, [...] assessment is integrated into classroom practice, and evaluation - the results of assessment provide important data for determining the effectiveness of the curriculum. ${ }^{47}$

When stating that "the results of assessment provide important data for determining the effectiveness of the curriculum," Graves was referring to teachers undertaking and analysing student evaluation at the end of their course. Through this process, as stated earlier, resulting changes to the curriculum typically only impact the next cohort of students. The proposed co-constructed curriculum model aims to extend the impact of student feedback: it aims to integrate student feedback through a direct dialogue with the teacher during the course of the teaching period. Current students are given a voice in determining the value and the effectiveness of the curriculum activities for their learning. More precisely they are expected to provide feedback on two components of the curriculum:

1. How, in their eyes, the curriculum's assessment tasks give them the opportunity to demonstrate evidence of achievement of the desired learning outcomes, and

2. How well the learning tasks have prepared them for these assessment tasks.

Such feedback does not happen spontaneously. It implies the establishment of an ongoing and active dialogue between teacher and students and a high degree of clarity and transparency regarding the choices and rationale adopted by the teacher during the initial curriculum design process. The dialogue between students and teacher needs to be informed by a series of clarifications from the part of the teacher, supported by a set of instruments, as described in Table 1 . The assessment context in the table below is the writing of three increasingly complex argumentative essays in French.

47 Graves, 'Language Curriculum,' p. 174. 


\begin{tabular}{|c|c|c|c|}
\hline & When & Clarification - Dialogue & Instruments \\
\hline 1 & $\begin{array}{l}\text { Before the } \\
\text { first } \\
\text { assessment } \\
\text { task }\end{array}$ & $\begin{array}{l}\text { Understanding task and alignment } \\
\text { Teachers' explanation of the task and how it is aligned } \\
\text { with some of the learning outcomes }\end{array}$ & $\begin{array}{l}\text { List of the learning } \\
\text { outcomes (CEFR } \\
\text { statements) pertinent } \\
\text { to the task }\end{array}$ \\
\hline 2 & & $\begin{array}{l}\text { Understanding the rubric } \\
\text { Teacher's presentation of the marking rubric. } \\
\text { Students attempt to mark the exemplar using the rubric. } \\
\text { Students discuss their evaluation in pairs. } \\
\text { Teacher reveals her evaluation of the exemplar. } \\
\text { Detailed discussion with students of the application of } \\
\text { the rubric. }\end{array}$ & $\begin{array}{l}\text { Assignment } \\
\text { exemplar (e.g. past } \\
\text { students' work) + } \\
\text { rubric + learning } \\
\text { outcomes }\end{array}$ \\
\hline 3 & & $\begin{array}{l}\text { Writing practice essay and grading practice } \\
\text { Students are asked to prepare an assignment similar to } \\
\text { assessment task } 1 \text { (on a different topic) and bring them } \\
\text { to class. } \\
\text { In pairs students mark their partner's assignment, using } \\
\text { the rubric. } \\
\text { Further clarification and discussion of the marking } \\
\text { criteria, corresponding learning outcomes and expected } \\
\text { standards of work. }\end{array}$ & $\begin{array}{l}\text { Rubric + learning } \\
\text { outcomes }\end{array}$ \\
\hline 4 & $\begin{array}{l}\text { After } \\
\text { completion } \\
\text { of the } \\
\text { assessment } \\
\text { task }\end{array}$ & $\begin{array}{l}\text { Analysing own work } \\
\text { Marked assignments given back to students with } \\
\text { annotated rubric. } \\
\text { Students are asked to complete the coded evaluation } \\
\text { sheet and compile types of errors. } \\
\text { They seek clarification of comments and grade from } \\
\text { teacher if needed. }\end{array}$ & $\begin{array}{l}\text { Rubric + coded } \\
\text { evaluation sheet }\end{array}$ \\
\hline 5 & & $\begin{array}{l}\text { Recommending curriculum improvement } \\
\text { Students assess how well learning activities prior to } \\
\text { assignment } 1 \text { have prepared them for the task and } \\
\text { recommend changes if necessary. }\end{array}$ & \\
\hline 6 & $\begin{array}{l}\text { Before } 2^{\text {nd }} \\
\text { assessment } \\
\text { task }\end{array}$ & $\begin{array}{l}\text { Seeking strategies \& curriculum support } \\
\text { Students are asked to revisit annotations and coded } \\
\text { errors from task } 1 \text { and choose strategies to remediate. } \\
\text { Students request types of learning activities and } \\
\text { materials in order to prepare for assignment } 2 \text {. }\end{array}$ & $\begin{array}{l}\text { Analysis of the } \\
\text { coded evaluation } \\
\text { sheet by student }\end{array}$ \\
\hline & & Steps 1-4 are repeated for assignments 2 and 3 & \\
\hline
\end{tabular}

Table 1. Co-constructed curriculum process

For the second assessment task, the assignment exemplar used in step 2 will be students' own first assignment, and so on for assignment 3. The coded evaluation sheet (steps 4 and 5) is a summary document that focuses on language and textual errors, i.e. on the "mechanics" of written expression. It has three sections: (1) accuracy (syntax, grammar), (2) sentence construction and (3) text structure-cohesion. These errors are not corrected by the teacher but coded so that students are aware of which types of errors they make most and have to find strategies to progressively reduce them. Over the course of the teaching period, there is an implicit contract with the teacher that students will aim at significantly reducing error types 1 and 2, mainly through autonomous work, and then concentrate their efforts on working on text cohesion and structure, which is the primary objective of the assessment task. 
The dialogic process, described in Table 1, is characterised by three main principles:

1. The development of a shared language between teacher and students,

2. The progression in complexity of the assessment tasks over the teaching period, and

3. Teachers' respect of students' feedback and recommendations for change.

Firstly, the explanations and discussion around the rubrics and the learning outcomes give students the means not only to decipher the level of performance expected in assessment tasks and the best strategies to prepare for them, but also to tell the teacher how well they feel the curriculum activities support them in achieving the desired outcomes for each assessment task. In other words, students are able and allowed to discuss the pedagogical rationale behind the series of curriculum activities planned by the teacher in preparation for an assessment task, and to suggest changes that would maximise this preparation. The wording of the CEFR competency statements, expressed in action-oriented 'can-do' statements, greatly assist students in their understanding of the learning outcomes for each task. The dialogue with the teacher can therefore focus on the expected level of performance and the criteria that will be used to assess standards of performance in that particular task.

Secondly, the dialogue between teacher and students has to be built up along comparable assessment tasks that are increasing in complexity. Rubrics become more demanding and the explanations and discussions more specific. As more and more examples are discussed and analysed, the "translation" of the CEFR competency statements into learning activities become progressively clearer to students. They get more and more competent in assessing their own work and analysing the gap between their performance and the standards of work expected.

Finally, and most importantly, students' feedback and recommendations have to be given due consideration by the teacher. In line with the democratic aspirations of the CEFR, the pedagogical dialogue between teacher and students has to be genuine and respectful of students' competence in matters related to their learning.

A dialogic and reflective relationship with students is to the teacher's benefit. Immediate student feedback is extremely powerful. Quality teaching that provides clear learning outcomes and transparent criteria, matched with aligned and coherent learning activities, is enhanced by students' assessment of the clarity and effectiveness of the curriculum in a spirit of collaboration and mutual support.

After reviewing thousands of studies involving millions of school students and investigating the factors that have the most influence on student learning, Hattie states that transparency of goals and methods, as well as feedback to and from the teacher, have great impact on the quality of student learning. ${ }^{8} \mathrm{He}$ coined the terms of "visible learning" and "visible teaching":

Visible learning' is teachers seeing learning through the eyes of students, and students seeing teaching as the key to their ongoing learning. The remarkable feature of the

$4^{8}$ John Hattie, Visible Learning: A Synthesis of 800 Meta-Analyses Relating to Achievement, Oxford: Routledge, 2009. 
evidence is that the greatest effects on student learning occur when teachers become learners of their own teaching, and when students become their own teachers. ${ }^{49}$

According to Hattie, visible teaching requires teachers to constantly review their own practice, and co-construct rather than simply instruct learning. ${ }^{\circ}$ In his study of "visible learning" in higher education, he deplores the fact that "often, learning in higher education involves students 'working out' what is to be learnt and what it means to be successful in that learning." ${ }^{1}$ The combination of coherent goals, assessment and learning tasks with feedback to teachers make learning and teaching visible, and create an environment highly conducive to quality learning. Students' feedback and interactive dialogue with the teacher help remove "the artificial ceiling imposed by learners' ignorance of quality." $5^{2}$ It leads to both enhanced learning and improved teaching. Students' informed feedback and the curriculum adaptations and modifications it engenders change and re-balance the relations of power in the Thirdspace that are language classrooms and associated learning environments.

\section{Conclusion}

The development and preliminary implementation of the co-constructed curriculum model was made possible by the availability of the CEFR's competency statements and their suitability to being integrated into the language curriculum as learning outcomes. Their focus on "can-do" abilities and experiential learning make them highly accessible to students. Since they generally outline concrete and "doable" actions, the broad relationship between the abilities they describe and the learning and assessing activities planned in the language curriculum is easily understood by students. The detailed learning path towards achieving the appropriate CEFR competencies require nevertheless progressive and transparent steps under the teacher's guidance. In a first stage, before the teaching period, these steps are necessarily programmed unilaterally by the teacher, with the prospective students' characteristics and needs in mind. During enactment, they require "student translation" and opportunities for students to constantly test their understanding of expectations and assessment requirements, and suggest modifications to the pathway predetermined by the teacher. The adjustments, additions and variations they recommend are the result of the influence and power given to them in a productive and cooperative environment. They are the mark of a functional relationship, beneficial to both teacher and students. Students feel part of the pedagogical discourse and develop a language and capacity to reflect on and analyse pedagogical processes, thus increasing their lifelong autonomous learning skills. Teachers get invaluable feedback from their students during teaching time and are placed in a position to experiment collaboratively with students, customise curriculum activities and research the impact on learning. Teachers need to be supported in adopting a more flexible approach to curriculum that welcomes ongoing student input. The co-constructed curriculum approach presented here attempts to provide a model for fostering the effective and professional dialogue necessary between learners and teacher in the establishment of a quality learning environment. The model has been piloted with a small number of language classes and its implementation needs

\footnotetext{
49 John Hattie, Visible Learning for Teachers. Maximizing Impact on Achievement, Oxford: Routledge, 2012, p. 14. 
to be extended. Initial research has shown that students greatly value the opportunity to influence and improve the curriculum, and the exercise of this opportunity significantly develops their understanding of both what is expected of them and how they can improve their learning and match these expectations. Further and more extensive research needs to be undertaken to investigate the impact of the model on the quality of student learning and student engagement in the curriculum design process. 